\title{
Impacts of Autonomous Vehicles on Traffic Flow Characteristics under Mixed Traffic Environment: Future Perspectives
}

\author{
Mohammed Al-Turki ${ }^{1, *}$, Nedal T. Ratrout ${ }^{1}$, Syed Masiur Rahman ${ }^{2}\left(\mathbb{D}\right.$ and Imran Reza ${ }^{3}$ \\ 1 Department of Civil \& Environmental Engineering, King Fahd University of Petroleum \& Minerals, \\ Dhahran 31261, Saudi Arabia; nratrout@kfupm.edu.sa \\ 2 Research Institute, King Fahd University of Petroleum \& Minerals, Dhahran 31261, Saudi Arabia; \\ smrahman@kfupm.edu.sa \\ 3 Department of Civil \& Architectural Engineering, University of Wyoming, Laramie, WY 82071, USA; \\ ireza@uwyo.edu \\ * Correspondence: moe_kt@hotmail.com; Tel.: +966-56-824375
}

\section{check for}

updates

Citation: Al-Turki, M.; Ratrout, N.T.; Rahman, S.M.; Reza, I. Impacts of Autonomous Vehicles on Traffic Flow Characteristics under Mixed Traffic Environment: Future Perspectives. Sustainability 2021, 13, 11052. https://doi.org/10.3390/ su131911052

Academic Editors: Efthimios Bothos, Panagiotis Georgakis,

Babis Magoutas and Michiel de Bok

Received: 24 August 2021

Accepted: 2 October 2021

Published: 6 October 2021

Publisher's Note: MDPI stays neutral with regard to jurisdictional claims in published maps and institutional affiliations.

Copyright: (c) 2021 by the authors. Licensee MDPI, Basel, Switzerland. This article is an open access article distributed under the terms and conditions of the Creative Commons Attribution (CC BY) license (https:/ / creativecommons.org/licenses/by/ $4.0 /)$.

\begin{abstract}
Vehicle automation and communication technologies are considered promising approaches to improve operational driving behavior. The expected gradual implementation of autonomous vehicles (AVs) shortly will cause unique impacts on the traffic flow characteristics. This paper focuses on reviewing the expected impacts under a mixed traffic environment of AVs and regular vehicles (RVs) considering different AV characteristics. The paper includes a policy implication discussion for possible actual future practice and research interests. The AV implementation has positive impacts on the traffic flow, such as improved traffic capacity and stability. However, the impact depends on the factors including penetration rate of the AVs, characteristics, and operational settings of the AVs, traffic volume level, and human driving behavior. The critical penetration rate, which has a high potential to improve traffic characteristics, was higher than $40 \%$. AV's intelligent control of operational driving is a function of its operational settings, mainly car-following modeling. Different adjustments of these settings may improve some traffic flow parameters and may deteriorate others. The position and distribution of AVs and the type of their leading or following vehicles may play a role in maximizing their impacts.
\end{abstract}

Keywords: autonomous vehicle $(\mathrm{AV})$; road capacity; traffic stability; mixed traffic environment; regular vehicle $(\mathrm{RV})$; policy implication

\section{Introduction}

The term autonomous vehicle (AV) is usually referred to as an autonomous vehicle that is considered a fully automated vehicle with level 5 automation without connectivity capabilities [1]. It has a self-driving system that can perform all the driving and operational tasks without human conduction. AVs can be divided into connected and autonomous vehicles [1-3]. Connected vehicle (CV) technology and automatic driving are two different technologies [4]. The term CV refers to any type of vehicle, including the RVs; with connectivity capabilities that access the information of their surrounding vehicles or the traffic infrastructure.

The term AV may refer to different types of AVs in terms of vehicle automation. Different levels range from partial automation to full automation. Partial automation may help to improve human driving behavior by utilizing advanced assisting driving systems (ADAS). The main rule of such systems is to improve driving comfort, reduce human driving errors, minimize the necessity for physical road signals and vehicle insurance, and improve safety [4-6]. Most of these are based on adaptive cruise control (ACC) systems, which are available now in a wide range of the existing models of the RVs $[5,7]$. By automatically controlling the throttle or the brake, the ACC system can control the car-following behavior, such as adjusting its speed and providing a specified distance, 
location, and acceleration from the trajectory data by using on-board sensors [2,5,8-10]. These systems are considered partial (semi) automated vehicles that only offer autonomous longitudinal following control $[1,11]$. The cooperative adaptive cruise control (CACC) is an updated and improved driver assistance system built upon the ACC system. It uses more information collected from the advanced $\mathrm{V} 2 \mathrm{~V}$ communication technologies [7] to automatically adjust the longitudinal control depending on the behavior of its leading and following vehicles $[7,8,12]$. With both ACC and CACC systems, the drivers are still responsible for actively steering the vehicle, keeping lanes, and monitoring traffic conditions. However, unlike ACC systems, CACC has direct communication with the vehicles ahead, using dedicated short-range communication (DSRC), which can enlarge the detection range of the distance sensors [4], it can provide a range of $3000 \mathrm{ft}$ in diameter with the possibility of an extended range using multiple transmitters [13]. As a result, compared to ACC, CACC can gather more information which enables more accurate and effective performance in a faster manner $[2,9,14]$.

$\mathrm{AV}$ implementation may lead to several impacts on urban mobility and city design [15]. $\mathrm{AVs}$ may lead to an increase in urban sprawl, resulting in increased travel time, energy consumption, and air pollutants [15]. Additionally, AVs will have impacts on individual travel behavior such as trip generation, mode choice, vehicle ownership, and travel time [16-18]. Hamadneh and Esztergar-Kiss (2019) compared the behavior of travelers before and after AV implementation assuming travelers are willing to wait and share their trips with others [17]. Their results indicated that a single shared $\mathrm{AV}$ could replace eight $\mathrm{RVs}$, reducing travel time and travel distance by $17 \%$ and $20 \%$, respectively. In their recent study, Hamadneh and Esztergar-Kiss (2021) aimed to consider the mixed traffic conditions of AVs with conventional transport modes, including RVs [18]. Their results indicated that the travel time decreases as $\mathrm{AV}$ implementation increases.

In the case of a traffic environment which includes only RVs, the stochastic nature of human driving behavior is critical to determining traffic flow efficiency and road operational capacity [13] and traffic stability [19]. The reaction times, desired speed, selected headways, and safe distance in addition to their heterogeneous reactions to traffic disturbances, such as performing lane changes or applying sudden brakes, are examples of such behaviors $[13,20]$. Although the main objective of AV implementation in traffic networks is to improve the comfort and safety of users, and environmental benefits during their mobility, AV's role could be pivotal in improving traffic flow characteristics [21]. Both RVs and AVs take the same amount of road space; however, the implementation of AVs will lead to different impacts on the traffic system. The exchange of information through the vehicle to vehicle (V2V) and vehicle to infrastructure (V-I) communications may help the AV to adjust their driving behaviors based on real-time traffic conditions. In addition, the AV's expected impacts are mainly resulted from their unique operational characteristics, including car following, lane changing, speed, reaction times, and safety distance parameters. Compared to RVs, AVs will have a faster response to the different traffic conditions with better anticipation of the action of preceding vehicles [22-24]. Some studies showed that AVs have negligible reaction time delays as compared to RVs [25]. Furthermore, different reports showed that the AV implementation in the traffic flow might harmonize and increase the mean speed in the traffic flow $[19,25]$ and decrease the speed variability [23]. When the desired speed is set, the AV will barely deviate from this speed [22]. In addition, the acceleration and deceleration of AVs are generally much smoother than RVs [22]. Additionally, the AV will lead to shorter headways and safety distances in the flow [24,25]. Compared to RVs, AVs have smarter lane-changing maneuvers in lane changing [25]. Therefore, the implementation of AVs will cause fewer disturbances and less heterogeneity in the traffic leading to maximizing throughput in the traffic [8,24]. 
The adjusted characteristics impact the traffic flow elements such as road capacity parameters and the components of the traffic stability. The road capacity is mainly affected by different factors such as traffic composition, road conditions, and driving behaviors of the vehicles. Traffic composition, including the vehicle type with their specific driving behavior and the penetration of each type, is a significant factor that may affect the capacity [4]. Capacity is highly dependent on the longitudinal time headways and the lateral movements of vehicles [22]. Traffic flow stability is also an important parameter that determines the efficiency of the traffic networks. Traffic stability indicates maintaining the traffic capacity without a traffic breakdown incident. When traffic volume exceeds capacity, automobiles are compelled to perform cyclic acceleration-deceleration operations, resulting in unstable traffic flows influenced by the creation and spread of shockwaves $[13,20]$. One of the important factors in this regard is the speed and time gap distributions. With a smaller standard deviation, the flow will be more stable, and there will be fewer unexpected breakdowns. Traffic hysteresis and oscillations develop in the flow due to automobile lane-changing and car-following behavior [13]. Examples may include lane changes near merges and diverge section, lane drops, or changes of road geometrics.

Due to its improved operational characteristics, the implementation of the $\mathrm{AV}$ is expected to overcome the problems of stochastic human driving behavior and positively impact traffic flow efficiency. Several studies have investigated the possible impacts of AV implementation for either complete AV or mixed traffic environments with RVs. Due to the lack of available observed traffic data, most of these studies focus on modeling and simulation. Based on the literature review, it appears that there are limited numbers of papers that reviewed the impacts of $\mathrm{AV}$ implementation on different related aspects. Hoogendoorn et al. (2014) reviewed the general impacts of AVs on traffic flow efficiency [23]. Narayanan et al. (2020) reviewed the contributing factors affecting the impacts of AVs [1]. Most of the published papers focused on reviewing the impacts on traffic systems assuming a complete AV environment. Additionally, the literature indicated that a large proportion of papers focused on the impacts of the partial automation level of AVs. However, it is expected that the implementation of different types of AVs, including complete AV level in the traffic environment, will occur gradually, and therefore, it will cause different impacts on the traffic system. None of the published reviews adequately focused on reviewing the impacts on the traffic flow characteristics under a mixed traffic environment with RVs.

This review study aims to fill the critical research gap in the future development of AVs in urban networks. The main objective of the current study was to include and discuss an extended review of the above-mentioned topic under partial AV implementation. The concepts of road capacity and traffic stability were considered to analyze the impacts of the AVs on the traffic flow characteristics. Unlike other reviews in the literature, this review discussed the impacts under different important aspects of the topic, such as different types of AVs representing different automation levels and connectivity capabilities and network types to enhance the analysis capacity for some meaningful findings. Based on the findings of the current review, a policy implication was included to significantly help the traffic community to maximize the benefits of $\mathrm{AV}$ implementation by developing effective policies for future traffic operation and control under a mixed traffic environment.

The remaining sections of this paper are organized as follows. Section 2 includes the research methodology of the paper. Section 3 includes a brief discussion of the impacts of the complete AV implementation. In Section 4, a comprehensive literature review of the different related studies is included considering different types of AVs under partial AV implementation. In Section 5, the primary factors of the impacts of AV implementation on mixed traffic environments are discussed in detail. Section 6 includes a policy implications discussion that intended to provide a holistic lens to the interpretation of the main findings of this research for the actual future practice and further research interests. Finally, Section 7 includes the conclusions and recommendations of this work. 


\section{Research Methodology}

Despite covering an enormous body of literature, which is still growing, this study includes a systematic review that aimed at finding the impacts of different types of AVs (e.g., ACC, CACC, AV, CAV) on the traffic capacity and stability under mixed traffic environment with the RVs (Figure 1). The planning part of this systematic review entails creating the study purpose and question, keywords, and a set of inclusion and exclusion criteria. Thus, "autonomous vehicle", "road capacity", "traffic stability", and "mixed traffic environment" were selected to be the search keywords. The inclusion criteria were specified to peer-reviewed journal papers published in English and related to the research objective. However, this review has ignored the impacts of AVs on traffic safety, travel planning, including travel time and road choice, driver comfort, environmental issues, and economic and social impacts. The impacts related to the application of the platooning concept or the use of dedicated AV lanes in the traffic network were not considered. The selected publications are mainly related to investigating the impacts of AVs on the traffic characteristics in mixed traffic environments sharing the same traffic network lanes with other different types of vehicles, including RVs. The search's first publishing date was not specified; however, April 2021 was chosen as the end date. The following limitations should be noted in this review approach: (a) exclusion of non-peer-reviewed full-text papers that are freely available online, including conference proceedings, book chapters, and white papers, and (b) unintentional bias of the authors may influence how the review and findings are carried out and interpreted. The second phase entails the reviewing of pertinent articles. Throughout the extraction procedure, the complete contents of the publications were searched and read. At the beginning of this stage, according to differing levels of complexity, the AV types are divided into three main categories. For each category, critical ideas about representative models are reviewed and explained. Furthermore, their impacts on road capacity and traffic stability are critically reviewed along with their critical related factors. In general, the distinctions and links that connect traffic flow and AV driving behavior under a mixed traffic environment are extensively discussed in this research. 


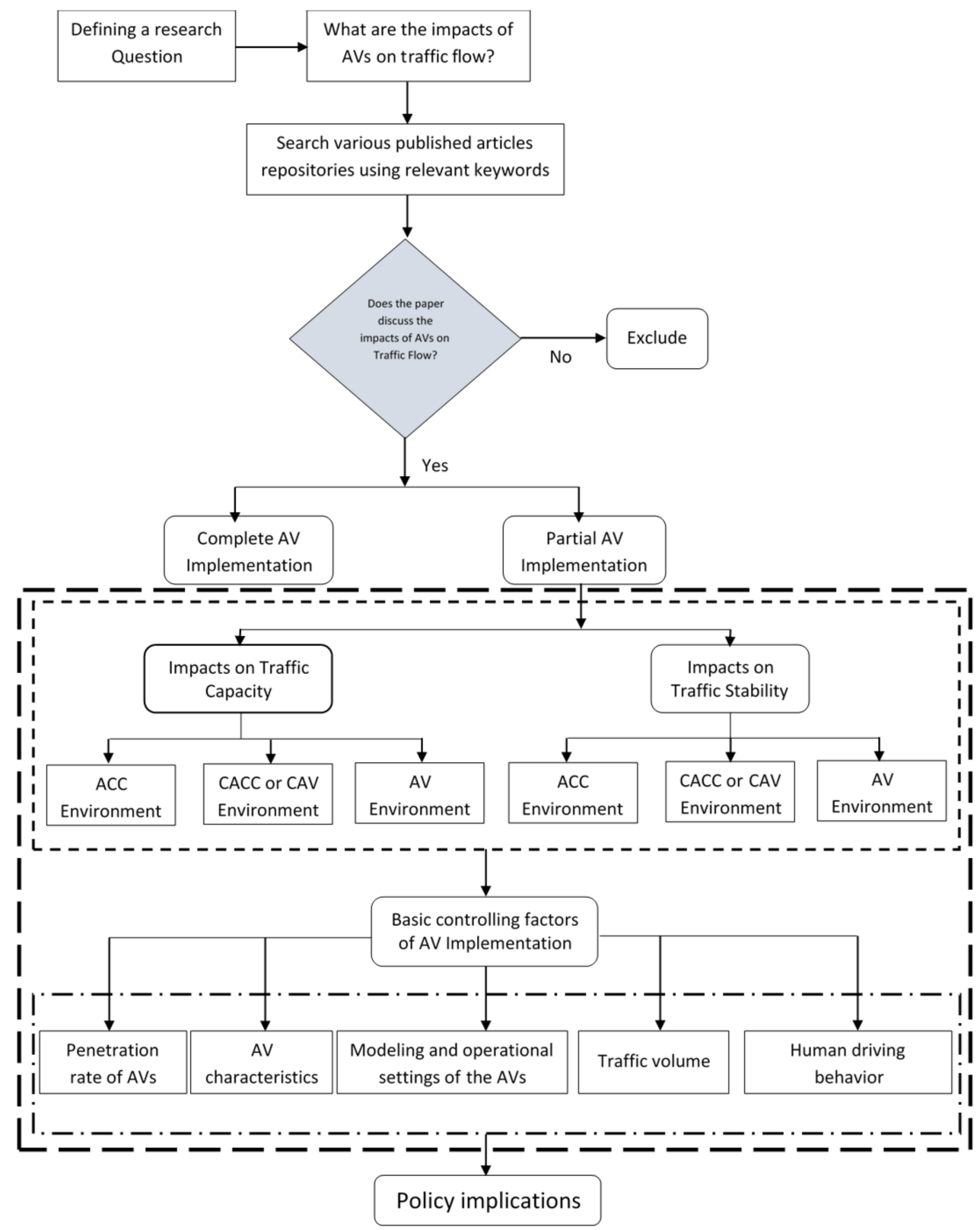

Figure 1. Methodology flowchart.

\section{Impacts of the Complete AV Implementation}

Many related studies have been conducted to evaluate the impacts of the complete implementation of different types and models of AVs in traffic networks. In general, most of these studies have confirmed that the complete implementation has positive impacts on the traffic flow characteristics, mainly in terms of improved traffic capacity. For example, Van Arem et al. (2006) concluded that complete CACC implementation increases the traffic flow and capacity in the highway system [26]. Tientrakool et al. (2011) concluded that compared to a complete RV environment, a complete CACC environment in the urban network increases the capacity by $273 \%$ [27]. Shladover et al. (2012) concluded that the capacity of CACC traffic is doubled compared to a RV environment [28]. Bohm and Häger, (2015) showed that when the traffic volume is high, the complete AV (Level 3) traffic increases the capacity parameters compared to the complete environment of RVs [29]. The delay and number of stops decreased by $56 \%$ and $54 \%$, respectively, while the speed increased by $34 \%$. However, in the case of low volume, the delay increased by $1.3 \%$, speed decreased by $0.38 \%$, 
and the number of stops increased by $2.9 \%$. Maurer et al. (2016) found that compared to complete RVs, the capacity of complete AV environment increased by $40 \%$ and $80 \%$ in urban network and highway respectively, using the improved symmetric two-lane cellular automaton (STCA) model. They concluded that the capacity with complete AVs increase from $2000 \mathrm{veh} / \mathrm{h}$ at $0 \%$ penetration rate of AVs to $3070 \mathrm{veh} / \mathrm{h}$ [30]. Mena-Oreja et al. (2018) also confirmed that, based on the proper selection of the maximum platoon length and the desired gap, the traffic flow of the complete CACC will increase by almost $39 \%$ compared to complete RV traffic [31]. The findings from Abdulsattar et al. (2020) also supported that a complete CAV environment will improve capacity by $250 \%$ compared to RV traffic in multi-lane highway systems [13]. In contrast to the above findings, Lu et al. (2020) contradicted the significantly improved capacity of the complete CAV implementation [24].

\section{Impacts of Partial AV Implementation}

Different studies in the literature have investigated the possible impacts of partial implementation of AVs on traffic flow characteristics under a mixed traffic environment. This literature included all of the related published studies during the period from 2003 up to 2020. Tables 1-3 summarize the main findings of these studies, respectfully, for the three categories: ACC environment, CACC and CAV environment, and AV environment, respectively. The variables of each study, including AV type, network type, and the study type, are included. The following parts of this section will discuss these findings concerning the two main traffic characteristics: traffic capacity and stability for each AV type. The next section of the paper will include an extended discussion about the primary factors of the impacts of AV implementation on a mixed traffic environment.

Table 1. Review of the studies related to the impacts of ACC on the traffic flow characteristics.

\begin{tabular}{|c|c|c|c|c|}
\hline \multirow{2}{*}{ Study } & \multicolumn{3}{|c|}{ Study Variables } & \multirow{2}{*}{ Main Findings } \\
\hline & AV Type & $\begin{array}{c}\text { Network } \\
\text { Type }\end{array}$ & Study Type & \\
\hline [32] & ACC & $\begin{array}{l}\text { Multi-lane } \\
\text { highway }\end{array}$ & Simulation & $\begin{array}{l}\text { - Flow increased by } 3 \% \text { per } 10 \% \text { increase of the penetration rate of ACC. Outflow increased } \\
\text { by } 2.4 \% \text { per } 10 \% \text { increase of the rate of ACC } \\
\text { Low rates of ACC }(25 \%) \text { can decrease congestions }\end{array}$ \\
\hline [33] & ACC & $\begin{array}{l}\text { Closed ring } \\
\text { road }\end{array}$ & $\begin{array}{l}\text { Meso- } \\
\text { simulations }\end{array}$ & $\begin{array}{l}\text { - } \quad \text { Low rates of ACC increased the capacity } \\
\text { - } \quad \text { Increased rate of RVs caused high susceptibility of congestion }\end{array}$ \\
\hline$[34]$ & $\mathrm{ACC}$ & $\begin{array}{l}\text { Single-lane } \\
\text { and ring } \\
\text { roads }\end{array}$ & Simulation & $\begin{array}{l}\text { - With time gaps less than } 1.1 \mathrm{~s} \text {, capacity rose linearly with increasing ACC rate; however, } \\
\text { with time gaps greater than } 1.5 \mathrm{~s} \text {, capacity declined as rates of ACC led to more improved } \\
\text { stability }\end{array}$ \\
\hline$[8]$ & ACC & Highway & $\begin{array}{l}\text { Macroscopic } \\
\text { analysis }\end{array}$ & - $\quad$ ACC improved the stability and increased the flow \\
\hline [22] & ACC & $\begin{array}{l}\text { Multi-lane } \\
\text { road }\end{array}$ & $\begin{array}{l}\text { Simulation } \\
\text { (considered } \\
\text { lane } \\
\text { changing) }\end{array}$ & $\begin{array}{l}\text { - } \quad \text { ACC had negative impacts on the flow and capacity } \\
\text { The positive impacts were found at rates above } 70 \% \\
\text { The capacity drop was slightly higher with the ACC implementation and was increasing } \\
\text { as the rate increasing } \\
\text { Decreased lane changes did not show significant impacts }\end{array}$ \\
\hline [35] & ACC & $\begin{array}{l}\text { Multi-lane } \\
\text { highway }\end{array}$ & $\begin{array}{l}\text { Micro- } \\
\text { simulation }\end{array}$ & $\begin{array}{l}\text { - ACC performance was highly affected by the parameter settings. Inappropriate settings } \\
\text { increased the collision risks and caused traffic disturbances } \\
\text { Optimal settings are expected to be different for different traffic conditions } \\
\text { - } \quad \text { Higher time gaps and deceleration rates improved stability and safety; but it decreased } \\
\text { capacity }\end{array}$ \\
\hline [36] & ACC & Highway & Review & $\begin{array}{l}\text { - Classical ACC increased the speed disturbance due to long time headway, however, the } \\
\text { dynamic rules of modified ACC types decreased it and therefore that improved the flow } \\
\text { - The likelihood of a traffic breakdown is determined by the ACC's dynamic parameters }\end{array}$ \\
\hline
\end{tabular}


Table 2. Review of the studies related to the impacts CACC and CAV on the traffic flow characteristics.

\begin{tabular}{|c|c|c|c|c|}
\hline \multirow{2}{*}{ Study } & \multicolumn{3}{|c|}{ Study Variables } & \multirow{2}{*}{ Main Findings } \\
\hline & AV Type & $\begin{array}{l}\text { Network } \\
\text { Type }\end{array}$ & $\begin{array}{l}\text { Study } \\
\text { Type }\end{array}$ & \\
\hline$[37]$ & CACC & $\begin{array}{l}\text { Multi-lane } \\
\text { highway }\end{array}$ & Simulation & $\begin{array}{l}\text { - Partial CACC implementation increased the flow from } 2100 \text { (with } 100 \% \text { RVs traffic) to } 2900 \text { (with } \\
20 \% \text { RVs, } 20 \% \text { ACC, } 60 \% \text { CACC traffic) } \\
\text { - A critical time gap of } 1.4 \text { sec was found to be the limit between the deterioration and improvement }\end{array}$ \\
\hline [26] & CACC & Highway & Simulation & $\begin{array}{l}\text { - At low traffic volumes, no significant impacts of different rates of CACC } \\
\text { At high traffic volumes, increased CACC rates improved stability, increased throughput, and } \\
\text { speed, and decreased shockwave impacts } \\
\text { With rates less than } 40 \% \text {, the impacts were minimal }\end{array}$ \\
\hline$[38]$ & CACC & $\begin{array}{l}\text { Single-lane } \\
\text { highway }\end{array}$ & Simulation & $\begin{array}{l}\text { - Increased headway variability due to the mixed traffic had minor impacts on the stability } \\
\text { - } \quad \text { CACC quickly damped shockwaves at low rates }(50 \%) \text {, and that improved more with higher rates }\end{array}$ \\
\hline$[27]$ & CACC & $\begin{array}{l}\text { Urban } \\
\text { signalized } \\
\text { intersec- } \\
\text { tion }\end{array}$ & $\begin{array}{l}\text { Capacity } \\
\text { analysis }\end{array}$ & $\begin{array}{l}\text { - Compared to complete RV, complete ACC increased the capacity by } 43 \% \text {, while complete CACC } \\
\text { increased it by } 273 \% \\
\text { Capacity increased slightly until the CACC rate exceeded } 85 \%\end{array}$ \\
\hline [28] & $\begin{array}{l}\text { CACC, } \\
\mathrm{ACC}\end{array}$ & $\begin{array}{l}\text { Single-lane } \\
\text { highway }\end{array}$ & $\begin{array}{l}\text { Micro- } \\
\text { simulation }\end{array}$ & $\begin{array}{l}\text { - ACC did not show improvement in the capacity; however, CACC significantly increased the } \\
\text { capacity mainly with higher rates } \\
\text { Increased rates of CACC had significant impacts on traffic flow, but the rate of ACC had minor } \\
\text { impacts }\end{array}$ \\
\hline [14] & CACC & & Review & $\begin{array}{l}\text { - The positive impacts of CACC on the stability and throughput were only found with CACC rates } \\
\text { of more than } 40 \%\end{array}$ \\
\hline [9] & $\begin{array}{l}\text { CACC, } \\
\text { ACC }\end{array}$ & $\begin{array}{l}\text { Three-lane } \\
\text { highway }\end{array}$ & $\begin{array}{l}\text { Micro- } \\
\text { simulation }\end{array}$ & $\begin{array}{l}\text { - } \quad \text { Platoon size had small impacts on the capacity } \\
\text { - } \quad \text { Capacity was increasing as the rate of CACC increasing }\end{array}$ \\
\hline [39] & $\begin{array}{l}\text { CACC, } \\
\text { ACC }\end{array}$ & $\begin{array}{l}\text { Urban } \\
\text { road }\end{array}$ & $\begin{array}{l}\text { Field } \\
\text { testing }\end{array}$ & - $\quad$ CACC increased the capacity and improved the stability \\
\hline$[40]$ & CACC & $\begin{array}{l}\text { Four-lane } \\
\text { highway }\end{array}$ & Simulation & $\begin{array}{l}\text { - } \quad \text { CACC implementation increased the capacity and improved the stability } \\
\text { - At low traffic volume, no significant impacts of different penetrations rates } \\
\text { - }\end{array}$ \\
\hline [41] & CAV & $\begin{array}{l}\text { Signalized } \\
\text { intersec- } \\
\text { tion }\end{array}$ & $\begin{array}{l}\text { Micro- } \\
\text { simulation }\end{array}$ & CAVs with a smoother acceleration/deceleration profile had negative impacts on capacity \\
\hline [34] & $\begin{array}{l}\text { CACC, } \\
\text { ACC }\end{array}$ & Highway & $\begin{array}{l}\text { Numerical } \\
\text { simulation }\end{array}$ & $\begin{array}{l}\text { - } \quad \text { Compared to ACC, CACC improved the stability } \\
\text { - } \quad \text { CACC increased the capacity and improved traffic dynamics, mainly at on-ramp bottlenecks }\end{array}$ \\
\hline [8] & CAV, AV & $\begin{array}{l}\text { Single-lane } \\
\text { highway }\end{array}$ & $\begin{array}{l}\text { Micro- } \\
\text { simulation }\end{array}$ & $\begin{array}{l}\text { - } \quad \text { CAV enabled a more reliable driving experience than AV } \\
\text { CAV with shorter headway increased the capacity and improved stability even at low rates } \\
\text { - CAV with longer headway decreased the capacity and increased delays; however, it improved } \\
\text { stability }\end{array}$ \\
\hline [11] & $\begin{array}{l}\text { CACC, } \\
\mathrm{ACC}, \mathrm{AV}\end{array}$ & $\begin{array}{l}\text { Urban } \\
\text { signalized } \\
\text { intersec- } \\
\text { tion }\end{array}$ & Simulation & $\begin{array}{l}\text { Different behavioral models and parameters of AVs had different impacts on traffic flow } \\
\text { - } \quad \text { AV penetration rate had similar impacts in urban networks and highways } \\
\text { Capacity and flow were increasing, and the delay was decreasing as the AV rate was increasing }\end{array}$ \\
\hline [4] & CAV & $\begin{array}{l}\text { Multi-lane } \\
\text { highway }\end{array}$ & $\begin{array}{l}\text { Simulation } \\
\text { (considered } \\
\text { lane } \\
\text { changing) }\end{array}$ & $\begin{array}{l}\text { - } \quad \text { CAV's capability to maintain shorter headways was negligible at lower rates } \\
\text { - Capacity increased with an increase of CAV rate, and that was more significant with rates of higher } \\
\text { than } 30 \% \\
\text { - Higher time gaps improved the stability and safety; however, it decreased the capacity }\end{array}$ \\
\hline
\end{tabular}


Table 2. Cont.

\begin{tabular}{|c|c|c|c|c|}
\hline \multirow{2}{*}{ Study } & \multicolumn{3}{|c|}{ Study Variables } & \multirow{2}{*}{ Main Findings } \\
\hline & AV Type & $\begin{array}{c}\text { Network } \\
\text { Type }\end{array}$ & $\begin{array}{l}\text { Study } \\
\text { Type }\end{array}$ & \\
\hline [42] & CAV & $\begin{array}{l}\text { Multi-lane } \\
\text { highway }\end{array}$ & $\begin{array}{l}\text { Simulation } \\
\text { (considered } \\
\text { lane } \\
\text { changing) }\end{array}$ & $\begin{array}{l}\text { As the rate of CAV increased, traffic flow became smoother owing to a reduction in excessive } \\
\text { deceleration rates. When rates of CAV are between } 40 \text { and } 50 \% \text {, the proportion of stop-and-go } \\
\text { traffic was decreased }\end{array}$ \\
\hline$[31]$ & CACC & $\begin{array}{l}\text { Multi-lane } \\
\text { road }\end{array}$ & $\begin{array}{l}\text { Micro- } \\
\text { simulation } \\
\text { (considered } \\
\text { platoon- } \\
\text { ing) }\end{array}$ & $\begin{array}{l}\text { - Compared to complete RV traffic, complete CACC traffic, with a maximum platoon length of } 2 \\
\text { vehicles and desired gaps of 10, } 5,1 \mathrm{~m} \text {, increased the flow by } 9.39 \%, 26.09 \% \text {, and } 39.21 \% \text {, } \\
\text { respectively, } \\
\text { with rates of less than } 20 \% \text {, capacity and flow decreased; however, with higher rates, capacity and } \\
\text { flow increased } \\
\text { Desired gaps and maximum platoon length were important factors of the capacity improvement }\end{array}$ \\
\hline [43] & $\begin{array}{l}\mathrm{AV}, \mathrm{ACC}, \\
\mathrm{CAV}\end{array}$ & Ring road & $\begin{array}{l}\text { Simulation } \\
\text { (considered } \\
\text { lane- } \\
\text { changing) }\end{array}$ & $\begin{array}{l}\text { - The average speed decreased, while density and congestion increased with increased rates of AVs } \\
\text { With high traffic volume scenarios, high rates of CAVs lead to increased capacity, smoother lane } \\
\text { changes, maintained high speed, and improved stability; however, low rates showed small } \\
\text { negative impacts } \\
\text { With low traffic volume scenarios, compared to RV traffic, the CAV's implementation showed } \\
\text { negative impacts even with higher rates }\end{array}$ \\
\hline [20] & CAV & $\begin{array}{l}\text { Single-lane } \\
\text { circular } \\
\text { road }\end{array}$ & Simulation & $\begin{array}{l}\text { - The portion of stop-and-go traffic decreased and led to improved stability with the increasing rate } \\
\text { of CAVs } \\
\text { - } \quad \text { Rates from } 10 \% \text { to } 50 \% \text { showed similar performance } \\
\text { - } \quad \text { CAV distribution did not show significant impacts }\end{array}$ \\
\hline [24] & CAV & $\begin{array}{l}\text { Urban } \\
\text { network }\end{array}$ & $\begin{array}{l}\text { Micro- } \\
\text { simulation }\end{array}$ & $\begin{array}{l}\text { - } \quad \text { Capacity, stability, and flow were improving with the increase of CAV rate } \\
\text { Flow significantly increased with } 50 \% \text { CAV rate }\end{array}$ \\
\hline$[44]$ & $\begin{array}{l}\text { ACC } \\
\text { CACC }\end{array}$ & $\begin{array}{l}\text { Multi-lane } \\
\text { highway }\end{array}$ & $\begin{array}{l}\text { Numerical } \\
\text { simulation } \\
\text { (consid- } \\
\text { ered lane } \\
\text { changing) }\end{array}$ & $\begin{array}{l}\text { - An increase in CACC rate significantly decreased traffic congestion and improved the capacity and } \\
\text { stability } \\
\text { - ACC implementation did not show any improvement in the stability }\end{array}$ \\
\hline$[1,44]$ & CAV & Highway & Simulation & $\begin{array}{l}\text { - } \quad \text { CAV with longer time gaps improved stability and safety; however, it decreased the capacity } \\
\text { - The level of the impacts was increasing with the increase in the rate of CAV }\end{array}$ \\
\hline [7] & $\begin{array}{l}\mathrm{CV}, \mathrm{AV}, \\
\mathrm{CAV}\end{array}$ & $\begin{array}{l}\text { Network } \\
\text { level }\end{array}$ & $\begin{array}{l}\text { Meso- } \\
\text { simulation }\end{array}$ & $\begin{array}{l}\text { - } \quad \text { V s and AVs, mainly with higher rates, led to significant improvement in traffic flow, capacity; } \\
\text { however, AVs were more significant than CVs }\end{array}$ \\
\hline [13] & CAV & $\begin{array}{l}\text { Multi-lane } \\
\text { highway }\end{array}$ & $\begin{array}{l}\text { Simulation } \\
\text { (considered } \\
\text { lane } \\
\text { changing) }\end{array}$ & $\begin{array}{l}\text { - CAV significantly increased the capacity with high rates ( } 50 \% \text { and above); however, lower rates } \\
\text { (less than } 40 \% \text { ) did not show improvement } \\
\text { The capacity in the free flow was directly proportional with the rate of CAV }\end{array}$ \\
\hline [45] & CAV & $\begin{array}{l}\text { Multi-lane } \\
\text { highway }\end{array}$ & $\begin{array}{l}\text { Micros } \\
\text { simulation } \\
\text { (considered } \\
\text { lane } \\
\text { changing) }\end{array}$ & $\begin{array}{l}\text { - The average lane change of RVs increased till } 30 \% \text { rate of CAVs was reached. After that, it } \\
\text { decreased as CAVs rate increased }\end{array}$ \\
\hline [46] & CAV & $\begin{array}{l}\text { A } \\
\text { single-lane } \\
\text { ring road }\end{array}$ & $\begin{array}{l}\text { Numerical } \\
\text { simula- } \\
\text { tions }\end{array}$ & $\begin{array}{l}\text { - Stability was related to the driver's reaction delay, rate of CAV, and the information obtained by } \\
\text { CAVs } \\
\text { - CAV implementation increased the traffic flow } \\
\text { - } \quad \text { Driver's reaction delay decreased the stability } \\
\text { As the rate of the CAVs increased, stability improved, and the propagation of lead vehicle } \\
\text { disturbance gradually disappeared }\end{array}$ \\
\hline
\end{tabular}


Table 3. Review of the studies related to the impacts of AVs on the traffic flow characteristics.

\begin{tabular}{|c|c|c|c|c|}
\hline \multirow{2}{*}{ Study } & \multicolumn{3}{|c|}{ Study Variables } & \multirow{2}{*}{ Main Findings } \\
\hline & AV Type & $\begin{array}{l}\text { Network } \\
\text { Type }\end{array}$ & Study Type & \\
\hline [23] & $\mathrm{AV}$ & & Review & $\begin{array}{l}\text { - } \quad \text { AV implementation had positive impacts on the capacity and stability } \\
\text { - } \quad \text { Congestion delay decreased by } 30 \%, 60 \% \text { with } 10 \%, 50 \% \text { rates of AVs, respectively } \\
\text { - Impact of AVs was highly affected by the time headway and speed choice }\end{array}$ \\
\hline [29] & $\begin{array}{l}\text { Full AV (level } \\
\text { 3) }\end{array}$ & $\begin{array}{l}\text { Urban } \\
\text { network }\end{array}$ & Simulation & $\begin{array}{l}\text { - With high traffic volume scenarios, complete AV traffic increased the capacity, decreased } \\
\text { delay and number of stops by } 56 \% \text { and } 54 \% \text {, and increased speed by } 34 \% \\
\text { With low volumes scenarios, complete } \mathrm{AV} \text { traffic increased the delay by } 1.3 \% \text {, decreased } \\
\text { speed by } 0.38 \% \text {, and increased the number of stops by } 2.9 \%\end{array}$ \\
\hline [47] & AV & $\begin{array}{l}\text { Highway } \\
\text { and } \\
\text { signalized } \\
\text { intersection }\end{array}$ & $\begin{array}{l}\text { Mathematical } \\
\text { modeling }\end{array}$ & $\begin{array}{l}\text { - } \quad \text { Capacity increased as the rate of AVs increased } \\
\text { A single RV in the lane decreased the speeds and therefore decreased the capacity } \\
\text { improvement }\end{array}$ \\
\hline [48] & AV & $\begin{array}{l}\text { Different } \\
\text { network } \\
\text { levels }\end{array}$ & $\begin{array}{l}\text { Macro- } \\
\text { simulation }\end{array}$ & $\begin{array}{l}\text { - At high volume scenarios, the capacity of traffic signals was doubled, however, at low } \\
\text { volumes, no improvement was found }\end{array}$ \\
\hline [25] & $\mathrm{AV}$ & $\begin{array}{l}\text { Multi-lane } \\
\text { highway }\end{array}$ & $\begin{array}{l}\text { Meso- } \\
\text { simulation } \\
\text { (considered } \\
\text { lane- } \\
\text { changing) }\end{array}$ & $\begin{array}{l}\text { AVs significantly improved the capacity, stability, and free-flow speed, mainly with high } \\
\text { rates } \\
\text { - Car-following maneuvers contributed more to the improvement than the smarter } \\
\text { lane-changing } \\
\text { - } \quad \text { Different lane-changing rules had minor impacts } \\
\text { Penetration rate of } 50 \% \text { was the optimal rate of lowering congestion level }\end{array}$ \\
\hline [49] & $\mathrm{AV}$ & $\begin{array}{l}\text { Multi-lane } \\
\text { highway }\end{array}$ & $\begin{array}{l}\text { Theoretical } \\
\text { framework }\end{array}$ & $\begin{array}{l}\text { - Strict segregation of AVs and RVs decreased the capacity; however, mixed-use policies } \\
\text { increased it }\end{array}$ \\
\hline [50] & $\mathrm{AV}$ & $\begin{array}{l}\text { Urban } \\
\text { network }\end{array}$ & Simulation & $\begin{array}{l}\text { - Slow improvement of network performance was observed until } 40 \% \text { AV rate; however, } \\
\text { after } 60 \% \text { rate, the performance degraded }\end{array}$ \\
\hline [51] & $\mathrm{AV}$ & $\begin{array}{l}\text { Single-lane } \\
\text { circular road }\end{array}$ & $\begin{array}{l}\text { Field } \\
\text { experiment }\end{array}$ & $\begin{array}{l}\text { - AV improved the stability } \\
\text { A single AV significantly decreased the stop-and-go waves that were produced by } 20 \mathrm{RVs} \\
\text { around it } \\
\text { A } 5 \% \text { rate of AVs led to significant positive impacts on stability }\end{array}$ \\
\hline [52] & $\mathrm{AV}$ & $\begin{array}{l}\text { Single-lane } \\
\text { ring road }\end{array}$ & $\begin{array}{l}\text { Control- } \\
\text { theoretic } \\
\text { study }\end{array}$ & $\begin{array}{l}\text { - } \quad \text { AVs significantly suppressed the unstable waves and led to smoother flow } \\
\text { - Speed increased by more than } 6 \% \text {, with } 5 \% \text { rate of AV }\end{array}$ \\
\hline [19] & $\mathrm{AV}$ & $\begin{array}{l}\text { Single-lane } \\
\text { highway }\end{array}$ & $\begin{array}{l}\text { Numerical } \\
\text { experiment }\end{array}$ & $\begin{array}{l}\text { - } \mathrm{AV} \text { improved the stability and decreased the uncertainty of the RV behavior } \\
\text { - } \quad \text { Uncertainty of RVs was lower in congested conditions compared to the free flow } \\
\text { The improvement was more significant with high rates of AVs }(50 \%) \\
\text { Reaction time and position of AVs showed negligible impacts }\end{array}$ \\
\hline
\end{tabular}

\subsection{Traffic Capacity}

This part will include a discussion of the findings related to the impacts of AV implementation on the traffic capacity and its components for each AV type. Based on the literature, different research has shown that the implementation of different levels and types of AVs in the network will significantly impact the improvement of the traffic capacity. The following subsection includes detailed literature for each type.

\subsubsection{ACC Environment}

Some studies have shown that the implementation of ACC may have significant impacts on traffic capacity. For example, using the Enhanced Intelligent Driver Model (EIDM), Kesting et al. (2010) demonstrated that the ACC may increase traffic flow and recovery from traffic breakdowns mainly at higher penetration rates [32]. The maximum flow was increased by $0.3 \%$ per $1 \%$ increase in the penetration rate of ACC, and the outflow from traffic jams was increased $0.24 \%$ per $1 \%$ increase in the penetration rate of ACC. Even 
low penetration rates of ACC $(25 \%)$ can decrease traffic congestion. Jerath and Brennan (2012), using General Motors's car-following model, concluded that the ACC may increase the traffic capacity even at lower penetration rates [33]. The capacity and traffic flow increase mainly with increase in ACC penetration rates. Ntousakis et al. (2015) used different time-gap settings and different network levels to conclude that smaller time gaps increased the capacity linearly with the penetration rate [34]. In contrast to the above positive impacts [28], using realistic headway choices, ACC did not significantly increase the capacity of single-lane highways. Calvert et al. (2017) confirmed that ACCs with smaller than $70 \%$ penetration rates have a negligible negative impact on traffic capacity [22]. The capacity drop is slightly increased due to the increase in the ACC rate. Li et al. (2017), using modified IDM, indicated that ACC may reduce the capacity owing to higher time gaps and deceleration rates [35].

\subsubsection{CACC or CAV Environment}

Some studies have confirmed that the implementation of CACC or CAV together would have significant impacts on traffic capacity [53]. Different studies indicated the capacity improvement due to CACC implementation, predominantly with higher rates $[9,28,40]$. Milanés et al. (2013), based on a field test, confirmed that CACC would increase the capacity of urban networks due to the reduced inter-vehicular gaps [39]. Another study particularly focused on on-ramp bottlenecks and found that CACC increases the capacity and traffic dynamics [34]. CAV with shorter headways increases the flow and capacity mainly with an increase in the penetration rate [8]. This improvement was significant even with low penetration rates. However, the positive impacts of the $\mathrm{CAV}$ were observed only at high traffic volume scenarios with higher penetration rates [43]. The improved characteristics of the CAV, such as the reduction of the time headways, gaps, and reaction times lead to improved capacity. However, for the scenarios of low traffic volume, CAV did not perform well compared to RVs, even with higher penetration rates due to the CAV's inability to overcome the speed limits. Lu et al. (2020) and Zhou et al. (2020) also confirmed that CAV implementation increases the capacity $[24,44]$. Abdulsattar et al. (2020) confirmed these findings mainly with high penetration rates due to the short following distance between two consecutive CAVs [13]. In contrast to the above positive impacts, CAV implementation with long-desired time gaps decreases the capacity $[1,4,44]$. When the penetration rate of CACC is less than $20 \%$, the capacity and the flow decreased as resulted by a high number of aborted maneuvers due to the obstruction caused by RVs [31,43]. However, when the rate of CACC is more than $20 \%$, the capacity and flow increased which is also supported by previous studies.

\subsubsection{AV Environment}

Some studies have shown that the implementation of AVs may have significant impacts on traffic capacity [23]. The capacity and flow increase as the penetration rate of AVs increases [47]. Using different behavioral models of AVs, Bailey (2016) concluded that, as the AV penetration rate increases, the flow of the AV increases and the delay decreases [11]. Liu et al. (2017) also confirmed that the implementation of AVs significantly increases highway capacity [25]. Fakhrmoosavi et al. (2020) concluded that CVs and AVs increase the intersection capacity [7].

\subsection{Traffic Stability}

This subsection includes a discussion of the findings related to the impacts of AV implementation on traffic stability and its components for each AV type. The components include throughput (flow), speed, and shockwave formation and propagation, and traffic congestion. The following subsections include detailed literature for each type of traffic environment.

\subsubsection{ACC Environment}

Some studies have shown that the implementation of ACC has significant impacts on traffic stability. Ntousakis et al. (2015) concluded that higher penetration of ACC 
may improve traffic stability by reducing the intensity of congestion waves [34]. Li et al. (2017) showed that ACC with longer time gaps and higher deceleration rates improve the stability of highways [35]. In contrast to the above positive impacts, Zhou et al. (2020) concluded that the implementation of ACC in highway deteriorates the stability of traffic flow stability [43]. Kerner (2020) in his study informed that the classical ACC model causes speed disturbance due to the long headway and therefore deteriorate the stability by initiating traffic breakdowns. However, the improved ACC models decrease these disturbances and either do not have negative impacts or improve the stability [36].

\subsubsection{CACC or CAV Environment}

Implementation of CACC or CAV is expected to have significant impacts on traffic stability. Van Arem et al. (2006), using good vehicle dynamics and driver behavior models, concluded that higher penetration rates of CACC in high traffic volume scenarios significantly improve traffic stability, increase flow, reduce shockwave impacts, and increase the average speed [26]. Schakel et al. (2010), using the IDM+ car-following model, concluded that CACC improves traffic stability by the fast dampening of the shockwaves even with low penetration rates [38]. The simulation results of several studies confirmed the improved stability due to CACC implementation [39,40,54]. Narayanan et al. (2020) also confirmed that $\mathrm{CAV}$ with the application of long-desired time gaps decrease speed dispersion and improve traffic stability and safety [1]. Additionally, Talebpour and Mahmassani (2016) and Ye et al. (2018) supported the fact that CAV implementation improves stability by the reduction of shockwave impacts [8,42]. Makridis et al. (2018) concluded that CAVs had a positive impact on traffic stability which improves with the increase in penetration rates due to smoother lane changes and the maintained high speed of the CAV in high traffic volume scenarios [43]. Using the stochastic Lagrangian model, F. Zheng et al. (2019) concluded that CAVs improve the stability of the traffic flow by reducing the stop-and-go waves [20]. CAV implementation improves the stability and increases the flow mainly with the increase of CAV penetration [24]. Zhou et al. (2020) concluded that the increase of CACC penetration significantly decreases traffic congestion and improves traffic stability [44]. CAV implementation increases traffic flow; however, the information from vehicles ahead of CAV plays an important role [46]. In contrast to the above findings, Makridis et al. (2018) concluded that low penetration rates of CAVs led to minor negative impacts on traffic stability [43].

\subsubsection{AV Environment}

The review made by Hoogendoorn et al. (2014) indicated that AV implementation has positive impacts on traffic stability. Congestion delay can be decreased by $30 \%$ and $60 \%$ with $10 \%$ and $50 \%$ penetration rates of AVs, respectively, due to their increased throughput in traffic flow [23]. Liu et al. (2017) confirmed that AVs improve the traffic stability and increase the free-flow speed of the highway, mainly with higher penetration rates due to smart maneuvers of AVs [25]. Stern et al. (2018) confirmed that the AV implementation, even with lower penetration rates, could improve the stability by decreasing stop-and-go waves in the traffic [51]. A single AV can substantially decrease those waves produced by $20 \mathrm{RVs}$ around it in a circular road. Y. Zheng et al. (2020) concluded that AVs suppressed unstable traffic waves and increase the speed of the flow [52]. The speed increased by more than $6 \%$, with only $5 \%$ AVs. F. Zheng et al. (2020) also confirmed that AVs improved stability by decreasing speed variations in the traffic flow [20]. This improvement is prominent with higher penetration rates of AVs. Fakhrmoosavi et al. (2020) concluded that the implementation of CVs and $\mathrm{AVs}$ led to substantial improvements in traffic flow and faster recovery [7]. In contrast to the above findings, Makridis et al. (2018) concluded that the low penetration rate of $\mathrm{AV}$ had a negative impact on traffic stability [43]. The average speed decreased while density and congestion increased with increased penetration rates of AVs. 


\section{Basic Factors Controlling Impacts of AV Implementation in a Mixed Traffic Environment}

In general, the obtained results of the different studies somehow leave a space to dispute due to differences in their study types, tested AV type including their modeling and settings, network level, traffic composition, traffic conditions, and driver behavior. The relationship between the implementation of the AVs and their impacts on the mixed traffic environment of AVs and RVs is complex and is based on different factors. Modeling a mixed traffic requires countless and sophisticated interaction rules [6]. Some of the studies discussed the importance of some examples of those factors. The impacts of AVs on traffic stability are influenced by penetration rate, connection, platoon size, safe and desired gap, and driver behavior [20]. According to Jin et al. (2020), the stability of mixed traffic is dependent on the reaction time of drivers, the penetration rate of CAVs, and the information that CAVs may collect [46]. Narayanan et al. (2020) mentioned that there are 19 related factors, including acceleration and deceleration profiles, lane-changing rules, longitudinal driving behavior, presence of connectivity between AVs, desired gap, network level, vehicle distribution in the network, implemented optimization function, the use of dedicated lanes for CAVs and AVs, intersection control method, platoon size, and presence of VSL [1]. On the other hand, F. Zheng et al. (2020) concluded that the reaction time and the position of $\mathrm{AVs}$ are not considered as significant factors in terms of the AV's impacts on traffic stability. F. Zheng et al. (2020) concluded that there are no significant impacts of CAV's distribution on traffic stability [52].

This review has indicated that those discussed expected impacts of different types of $\mathrm{AV}$ in mixed traffic environments are depending on some basic factors that may affect the level and the magnitude of their impacts. These primary factors basically may include:

- Penetration rate of the AVs

- AV characteristics

- Modeling and operational settings of the AVs

- Traffic volume

- Human driving behavior in a mixed traffic environment

All these factors differ in their effects on the traffic flow impacts. Those factors, including their effects, are discussed in the following section.

\subsection{Penetration Rate of the $A V s$}

Most of the studies have investigated the expected impacts of different AVs on the mixed traffic environment using different penetration rates. For example, Van Arem et al. (2006) confirmed that the penetration rate of CACC is only critical with high traffic volumes scenarios and found that the critical rate that starts to indicate impacts is above $40 \%$ [26]. With low traffic volumes, there were no noticeable impacts of different penetration rates. Schakel et al. (2010) concluded that when the penetration rate increased, the duration of the shockwaves decreased, leading to improved stability [38]. Kesting et al. (2010) concluded that with increasing rates of ACC in highway, the flow and the outflow from traffic breakdowns increases [32]. Tientrakool et al. (2011) concluded that the capacity increased slightly until the CACC penetration rate exceeded $85 \%$ [27]. Jerath and Brennan (2012) concluded that low rates of ACC may lead to an increase in the congestion level [33]. Shladover et al. (2012) concluded that higher penetration rates of CACC are required to have significant positive impacts on the traffic flow [28]. The positive impacts on the stability and flow were noticed only when the penetration rate of CACC is above $40 \%$ [14]. The capacity increases as the penetration rate of AV increases [9]. Arnaout and Arnaout (2014) confirmed no significant impacts of different penetrations rates at low volume traffic scenarios. With high volume traffic scenarios, with penetration rates of less than $40 \%$, their impacts were minimal; however, when it is more than $40 \%$, the increase in CACC penetration rates leads to a significant increase in traffic flow. Ntousakis et al. (2015) also confirmed that higher penetration of ACC led to improved stability [44]. Narayanan et al. (2020) also supported that the traffic flow increases with the increase in the penetration 
rate of CAVs [1]. In addition, Talebpour and Mahmassani (2016) confirmed that higher penetration rates of CAVs can increase the flow and capacity of the traffic network [8]. On the other hand, Calvert et al. (2017) concluded that the critical penetration rate above $70 \%$ of ACC that may start to indicate an improvement in traffic flow. The increase of $\mathrm{AV}$ penetration rate improves the capacity, traffic stability, and free-flow speed [25]. The penetration rate of $50 \%$ is optimal in terms of lowering the congestion level. With the use of a proper time gap, capacity increases with an increase in CAV penetration rate, and it is more significant with rates higher than $30 \%$ [4]. When the penetration rate of CACC is less than $20 \%$, CACC has a negative impact on the traffic; however, when the rate is more than $20 \%$, it leads to an improvement [31]. Even low penetration rates of AVs, such as $5 \%$, lead to positive impacts on traffic stability [51]. Compared to RVs, AVs have negative impacts even at low penetration rates; however, higher rates, mainly in high volume traffic, exhibit some improvement [43]. The improvement of traffic capacity and stability increases with the increase in the penetration rate of CACC [44]. Lu et al. (2020) also confirmed that the penetration rate of AVs in mixed traffic highly impacts the capacity, stability, and flow. The capacity increase is high with $50 \%$ or more CAV penetration [24]. Using the stochastic Lagrangian model, F. Zheng et al. (2019) concluded that the stop-and-go traffic was decreased and the stability improved with an increasing penetration rate of CAVs [20]. However, the penetration rates of $10 \%$ to $50 \%$ showed similar performance. Higher penetration rates of CVs and AVs result in slightly higher flow and improved stability [7]. F. Zheng et al. (2020) concluded that the improvement of the traffic stability is more significant with high penetration rates (50\%) of AVs [52]. Abdulsattar et al. (2020) concluded that the capacity in the free-flow phase is directly proportional to the penetration rate of CAVs. In congested flow, less than $40 \%$ rates did not show improvement in the capacity [13]. The critical rate in terms of capacity improvement was found to be $50 \%$. Jin et al. (2020) found that when the penetration rate of CAVs goes up, stability improves, and lead vehicle disturbance propagation fades away. Many studies confirmed that the penetration rate of $\mathrm{AV}$ is highly an important factor that significantly affects the level of their impacts [46]. According to some studies, they even mentioned that the penetration rate is a critical factor only with high traffic volume conditions. However, few studies have indicated that with low penetration rates, there is no expected improvement, or it may even worsen the traffic conditions.

\subsection{AV Characteristics}

One of the important factors that highly affect the level of expected impacts of AV implementation in a mixed traffic environment is the characteristics of the implemented AV. Different AVs behave differently in the traffic flow due to their specific operational characteristics, and their impacts vary mainly in a mixed traffic environment. The performance of ACC systems depends only on the behavior of the leading vehicle. CACC or CAV have advanced communication capabilities that gather and utilize more information of the vehicles ahead or further downstream to automatically control the following longitudinal behavior based on its leading and following vehicles. Unconnected AV's conservative code of conduct and inability to forecast nearby vehicle's movements are the reasons for their potential decreased capacity to produce favorable traffic flow impacts [1].

Some studies have directly compared the expected impacts of these different types of $\mathrm{AV}$ under a mixed traffic environment. Compared to complete ACC traffic, complete CACC traffic showed significantly improved capacity [27]. ACC did not show a significant capacity improvement; however, CACC significantly improved the capacity [28]. CACC implementation improves the stability of traffic flow compared to ACC [54]. Overcoming the sensor constraints, $\mathrm{CAVs}$ can provide a smoother and more dependable driving experience than AVs [8]. CACC improves traffic stability while ACC causes instability of the traffic flow [44]. Therefore, AVs are more significant than CVs in enhancing the traffic flow and stability in the urban network [7]. 
In general, it may be concluded that the implementation of CACC or CAV is better than the non-connected AV or ACC in improving traffic capacity and stability. However, some factors could affect their positive impacts, including penetration rate and their distribution and position in the traffic flow and the type and the characteristics of the leading vehicle. If the preceding vehicle of the connected vehicle is non-connected, it does not positively impact the traffic flow. For example, the desired time headway may not be assumed as a fixed number if the $\mathrm{AV}$ follows a RV. Moreover, CAV allows closer gaps when following another $\mathrm{CAV}$, but if it follows an $\mathrm{RV}$ or non-connected $\mathrm{AV}$, its behavior is same as these vehicles [2]. According to Makridis et al. (2018), CAVs that follow AVs or RVs react as $\mathrm{AVs}$, since they do not have any information from other vehicles to use their connectivity capabilities [43]. At the lower rate of CAV penetration, the probability of connected platoon formation of CAV is lower than the probability of a CAV following RV or an AV [43]. It justifies the insignificant impacts of CAV at low penetration rates in mixed traffic environments due to their required longer headways. However, the lower reaction times of connected vehicles are achieved due to their radar detection systems [13].

On the other hand, the literature did not include a clear definition for these different types of AVs. It was noticed that some studies assumed that AVs are connected to other vehicles and have real-time information through V2I. For example, Talebpour and Mahmassani (2016) stated that different studies sometimes use automation and connectivity interchangeably [8]. Some studies did not specify the exact characteristics of the AV. However, to have reliable and logical comparable results with other studies in terms of evaluating the impacts of AVs, it is important to include a clear description of $\mathrm{AV}$ and $\mathrm{RV}$ characteristics, including their selected driving models, operational settings, and their connectivity capabilities with other objects in the traffic flow and other needed assumptions for modeling the AVs. In the current literature, we have tried our best, with available information in the studies, to specify the type of the used AVs within each study to have clear conclusions about their impacts.

\subsection{Modeling and Operational Settings of the AVs}

Bailey (2016) confirmed that different behavioral models and parameters of the AV may have different impacts on traffic flow. Some of the studies are discussed in the following subsection.

\subsubsection{Modeling of AVs}

Several driving models have been proposed in the literature for modeling different types of $\mathrm{AVs}$ for simulation works. Examples include the Intelligent Driver Model (IDM), Cooperative IDM, Gipps driver model, and different acceleration frameworks. Ntousakis et al. (2015) and Gora et al. (2020) in two different studies conducted a review on the existing microscopic modeling of ACC [34,55]. In general, the specific driving models of AVs involve two main groups: car-following and lane-changing models. The selection of car-following models is more critical than the lane-changing models. Liu et al. (2017) concluded that the car-following maneuvers of AVs confirmed contribute more to the improvement than lane changing. Lane-changing in traffic flow usually leads to longer time headways in the origin and destination lanes [25]. A vehicle requires a sufficient gap in the destination lane and leaving a gap in the origin lane. As a result, more lane changes could lead to negative impacts on the capacity. In terms of lane-changing modeling of AVs, few studies investigated the impacts of lane-changing behavior in a mixed traffic environment. The adjusted lane-changing behavior may cause some impacts on the traffic flow. Makridis et al. (2018) concluded that smoother lane changes of AVs improve capacity and stability [43].

In contrast, Liu et al. (2017) concluded that using different lane-changing rules of AVs had negligible impacts on traffic flow [25]. Calvert et al. (2017) concluded that the impacts of lane-changing modeling of ACC, such as fewer lane changes, do not show significant impacts [22]. 


\subsubsection{Operational Settings of the AV}

Each type of the AVs has a unique adjusted operational setting that controls its driving behavior and, therefore, differently affect its expected impacts on the traffic flow characteristics [56]. The selection of operational settings of car-following models of AV is an important factor. Hoogendoorn et al. (2014) concluded that the expected impacts of AVs are highly affected by the time headway and speed choice [23]. Li et al. (2017) also confirmed that ACC performance is highly affected by the parameter settings. Inappropriate parameter settings may increase the collision risks and therefore cause traffic instability [35]. However, the optimal parameters are expected to be different for different traffic conditions. The safe and desired gap settings and maximum platoon length are important factors for the expected capacity improvement due to CACC implementation [31]. Kerner (2020) concluded that the possibility of traffic instability is highly dependent on the dynamic parameters of ACC [36]. A few critical car-following settings include time and space headways, acceleration and deceleration rates, speed, and reaction time.

Different studies have indicated that the most important settings of AV are the settings of headway parameters. VanderWerf et al. (2004) concluded that a critical time gap of $1.4 \mathrm{sec}$ is the limit between the deterioration and the improvement of the traffic flow; however, that is valid only for when the penetration rate of CACC is higher than $60 \%$ [37]. Ntousakis et al. (2015) tested different time gap settings and concluded that the capacity improvement of mixed traffic of ACC and RV is highly dependent on these settings [34]. With time gaps of less than $1.1 \mathrm{sec}$, the capacity increased linearly with the increase in the penetration rate of ACC; however, with time gaps of $1.5 \mathrm{sec}$ or more, it decreased even when ACC penetration rate increased. Talebpour and Mahmassani (2016) also confirmed that CAVs with shorter headway increase the throughput and capacity mainly with higher penetration rates [8].

In contrast, the increased time headway has some negative impacts such as reduced capacity and increased delays; however, it may improve the traffic stability $[4,8,35]$. Calvert et al. (2017) also confirmed that with the partial implementation of ACC [22]. On the other hand, Ye and Yamamoto (2018) concluded that CAV's capability to maintain shorter headways is negligible at lower penetration rates [4]. Mena-Oreja et al. (2018) tested different time gaps settings in a complete CACC environment. They found that with the use of desired gaps of $10 \mathrm{~m}, 5 \mathrm{~m}$, and $1 \mathrm{~m}$, the flow increases by $9.39 \%, 26.09 \%$, and $39.21 \%$, respectively, compared to a complete RV environment [31]. Longer time gaps reduce speed dispersion and improve traffic stability and safety; however, they may decrease capacity [1]. Kerner (2020) confirmed that the possible large speed disturbance of ACC traffic results from their wide range of the long-desired time headway to the preceding vehicle [36].

Another critical aspect of the car-following driving models is the settings related to AV's speed distributions and acceleration/deceleration rates. For example, Le Vine et al. (2015) investigated the impacts of CAV at a signalized intersection and concluded that CAVs the operated with smoother acceleration/deceleration profile have negative impacts on capacity because of the restriction on the dynamics of the vehicles [41]. Li et al. (2017) also confirmed that higher deceleration rates improve stability and safety; however, that may decrease the capacity [35]. According to Ye et al. (2018), the smoother traffic flow with rising CAV penetration rate is attributable to a decrease in the percentage of high deceleration rate [42]. The negative impacts of the low implementation rates of the $\mathrm{AV}$ are due to their longer headways and lower maximum deceleration and acceleration compared to the RVs [43].

In general, the exact driving behavior of different types of AVs in mixed traffic environments is complex and still not understood [56]. Most of the studies are based on different assumptions of the driving behavior of AVs, such as car-following and lane-changing behavior. Some technical components regarding the modeling and simulation of AVs highly affect its obtained expected impacts indicated by these different studies. Zeidler et al. (2019) stated no common agreement or recommendations on parameter settings when modeling AVs in micro-simulation software [12]. Even with the same type of AVs, the different 
applied operational settings, mainly those related to time headways, may highly affect the traffic flow. The AV with shorter headways will lead to an increase in road capacity. That is confirmed by the inversely proportional relationship between the capacity and the minimum average time headway between the vehicles. However, some studies have concluded that short headways have negative impacts on traffic stability. So, the settings of the $\mathrm{AV}$ for the simulation are critical to explain or verify the different obtained findings.

\subsection{Traffic Volume}

Some studies have indicated that the traffic volume level affects the impacts of the different AVs in a mixed traffic environment. The significant impacts of the AVs will be clear only at high traffic volume scenarios. Van Arem et al. (2006) concluded that at low traffic volumes, there were no significant impacts of different penetrations rates of CACC on the traffic stability [26]. However, at high traffic flows, their impacts were significant. Arnaout and Arnaout (2014) also confirmed this in terms of improving the traffic flow due to CACC implementation [40]. Bohm and Häger (2015) confirmed that for a high traffic volume, complete AV implementation increased the capacity [29]. However, for low volumes, AVs deteriorated the traffic characteristics. Maurer et al. (2016) confirmed the increased capacity of signalized intersection due to the AV implementation in case of high traffic volumes, while the low traffic volumes indicated no improvement [30]. Makridis et al. (2018) also concluded that when the traffic volume was high, the impacts of CAVs were positive; however, when the volume is low, they have found that the RVs outperformed CAVs [43].

\subsection{Human Driving Behavior in a Mixed Traffic Environment}

As indicated earlier, it is known that the human driving behavior of the RVs and the automated driving behavior of the AVs are not the same. The driving behavior of RVs can vary depending on whether they are following another RV or a CAV [57]. Each has different driving models and logic. For example, with human driving, the acceptable safe time gap is determined based on the human's perception and reaction time that is highly affected by different factors such as the driver's experiences, vision abilities, and expectations about the behaviors of other vehicles including different types of AVs. Another example is that human drivers may take risks while driving, trying to predict the movement of nearby vehicles in the entire traffic stream in addition to the immediate vehicle $[8,43]$. It is highly expected that the implementation of AVs in the mixed traffic environment will cause some impacts on the driving behavior of RVs as a result of their interactions. However, the literature has indicated that there are still uncertainties regarding these impacts that may be justified by the limitation of the real data and complexity of the reliable simulation and modeling of this complex traffic environment. From the available reviewed related studies, it can be concluded that the human driving behavior of RVs, including their reactions and adaptation, may affect the expected impacts of AV implementation. Schakel et al. (2010) concluded that the increased headway variability, caused by mixed traffic of CACC and RVs, had negligible impacts on the traffic stability [38]. Jerath and Brennan (2012) concluded that any increase of the RV rate in mixed traffic with ACC leads to higher susceptibility of congestion [33]. Maurer et al. (2016) concluded that a single RV in the traffic lane may lead to slower speeds and decrease the improved capacity of the AV implementation [30]. On the other hand, high rates of AVs decrease the uncertainty of the RV behavior mainly in congested traffic conditions compared to free flow, where the heterogeneous behavior impacts are more significant due to increased mean speed variance [52]. The average lane change of RVs increases until 30\% penetration rate of CAVs is reached. After that, it decreases as CAVs penetration rate increases [45]. Jin et al. (2020) concluded that one of the main factors that may affect the impacts of CAV in mixed traffic is the driver's reaction delay, which may cause traffic instability [46]. Kerner (2020) concluded that if the dynamics of the AVs are qualitatively different from those of RVs, the AV decreases the capacity [36]. 


\section{Policy Implications}

The implementation of the $\mathrm{AV}$ will transform transportation systems and traffic flow characteristics depending on many associated factors. Eliminating human errors and providing real-time information on vehicles from the connected infrastructure and other vehicles can result in significant driving behavioral improvements. Many policymakers wonder how AVs will change the future traffic demands, and how that may affect the planning for different transportation infrastructures such as roads, parking, and public transportation systems, and whether strategies and laws should encourage or limit their implementation [58]. In order to formulate policies, the first step is to identify problems that need to be addressed, determine which issues require the greatest attention, and specify what the nature of the problem is [59].

The existing traffic environment of road networks mainly includes RVs and some different types of semi-autonomous vehicles with different driving assisting systems. However, in the coming future, it is expected that the penetration rate of different types of AVs, including the full AV level, in the traffic environment will increase and therefore, it will cause different impacts on the traffic systems. The findings of this review have confirmed these related impacts of its implementation on the traffic capacity and the components of traffic stability. Furthermore, it has confirmed some critical related factors that control the level and magnitude of the expected impacts. As a result, the traffic authorities and engineers need to consider the specific characteristics of different AV types and their expected impacts under different future traffic compositions to propose effective policies for future traffic operation and control. The primary outcomes of the included discussions in this research may be significantly utilized to achieve that. These policies are related to optimized AV driving parameters, such as desired speed and headway, under different traffic environment compositions or network levels. In addition, other essential policies can be related to the design or optimization of the traffic control systems, such as signalized intersection control under a shared environment of AVs and RVs. Such policies are critical to ensure traffic efficiency and safety in the actual practice of the AV traffic environment [60].

The findings indicated that the complete implementation of different AVs significantly increases the traffic capacity compared to a complete RV traffic environment. None of the studies have shown negative impacts on traffic stability under a complete AV environment; however, different studies logically assumed that full stability will be achieved. In the case of complete AV traffic, the desired driving parameters of the AVs can be controlled and optimized to achieve the optimum traffic flow parameters. The presence of connectivity between AVs is a very critical aspect of modeling. The implementation of CAVs enhances the efficiency and reliability of AV performance.

Due to different factors, it may take a very long time to reach a $100 \%$ implementation of the $\mathrm{AV}$ in our traffic networks. The findings have indicated that the partial implementation of the AVs has different impacts on the traffic flow characteristics. Some of the studies have indicated that it may lead to different levels of improvement and others have conflicted that due to different factors. The related investigation works have considered different $\mathrm{AV}$ types, different car-following models, and different operational driving settings. In general, ACC implementation increases traffic capacity and improves traffic flow stability, mainly with higher penetration rates.

In contrast, some other studies have indicated that ACC has negative impacts on capacity or stability. In terms of the CACC or CAV impacts, in general, most of the studies have also confirmed that their implementation may improve the capacity and stability mainly with higher penetration rates. In contrast, some studies have indicated that CACC or CAV negatively impact the capacity or stability when their penetration rate is low. Two reviewed studies by Narayanan et al. (2020) and the authors of [4] indicated negative impacts of CAV on traffic capacity at any rate. In terms of the AV impacts, in general, most of the studies have also confirmed that the AV may increase the capacity and improve the stability mainly with higher penetration rates. However, only one study concluded that the 
AVs may have negative impacts on traffic stability even with higher penetration rates [43]. None of the studies have indicated negative impacts of AVs on the capacity of a mixed traffic environment.

So, as indicated earlier, due to their improved operational characteristics, the implementation of AVs may offer several potential positive impacts that may improve the overall efficiency of traffic mobility. However, these expected impacts are based on some crucial factors that should be considered while evaluating the AV's impacts on the traffic flow under a mixed traffic environment. This is highly important to maximize its positive impacts with the complex interaction with RVs. These factors are mainly related to their penetration rate, $\mathrm{AV}$ characteristics, modeling and operational settings of the $\mathrm{AVs}$, and the level of the traffic volume, in addition to the impacts of human driving behavior.

The penetration rate of the AVs is the most critical factor that may affect its expected impacts in a mixed traffic environment. Most of the studies have confirmed that the level of the expected improvement increases as the penetration rate increase. According to this review, the critical penetration rate should be above $40 \%$ to have significant positive impacts on the traffic capacity and stability. The policymakers should encourage and support the implementation of AVs in traffic networks by proposing different strategies mainly in cities with high traffic density. Moreover, the connectivity capabilities of the AVs can highly affect the level and the magnitude of the expected improvement on the traffic flow mainly in the case of a mixed traffic environment. The review has indicated that the implementation of CAVs is better than the non-connected AVs in terms of improvement of traffic capacity and stability. This superiority is due to their significant advanced characteristics, such as their ability to communicate and obtain more valued information about the traffic, enabling smarter control of car-following and lane-changing maneuvers. That may benefit the vehicles to maintain a better driving behavior by allowing shorter headways between them, faster reaction times, and complex maneuvers, such as platooning and improved merging or lane changing, with fewer disturbances to the traffic flow [61]. All of that can result in more utilization and optimization of the road capacity. In contrast to the CAVs, the behavior of the non-connected vehicles is governed by specific theories. For example, the gap acceptance theory in which the driver has critical spacing to perform safe lane merging [2]. Narayanan et al. (2020) concluded that the policymakers should enforce laws to ensure connectivity between AVs to maintain significant positive impacts of the AV implementation [1]. The findings also indicated other important aspects that should be considered, while evaluating the impacts of different types of AVs is the position and the distribution of the AVs in the traffic flow in addition to the type of the following or leading vehicles of the AV. Most of the related studies in the literature have only focused on the penetration rates of each type, ignoring these important factors. However, in order to achieve the optimum policy for future traffic environment, it is highly important to conduct a reliable investigation considering several possible combinations regarding the type of each following or leading vehicle of an $\mathrm{AV}$ in the traffic flow considering different types of $\mathrm{AVs}$ in addition to the RVs.

On the other hand, the selection of the driving models of the AVs and their operational settings is also considered a critical factor of the expected impacts. Among them, these impacts mostly resulted due to the adjustment of the car-following driving behavior mainly the headways and speed settings. However, optimizing these settings is highly complex since these may lead to different impacts on different flow characteristics. In addition, these adjusted settings may cause several impacts on other aspects such as traffic safety and driver comfort. So, the policymakers should realize that the optimum selection of these parameters may depend on different factors such as the penetration rate of the AVs and the network level and other targeted objectives of the AV implementation. However, in terms of human driving behavior in a mixed traffic environment, the review has indicated that the possible negative impacts of the $\mathrm{AVs}$ on the RV deriving behavior may be gradually decreased with the increase of the AV's rates. Moreover, as recommended by Kerner (2020), future systems for AVs should be developed whose rules are consistent with those of RVs 
in which both the car-following and lane-changing models should learn from the driver behavior of the RV [36].

\section{Conclusions}

This paper included a comprehensive literature review to investigate the AV implementation impacts on the traffic flow characteristics under a mixed traffic environment with RVs. It summarized the main findings of the reviewed studies considering their specific study variables, including the AV's type, network type, and the study type. In addition, the paper discussed important related factors that may affect the level of the impacts.

The review has shown that most of the related studies focused on investigating the possible impacts of the complete implementation of the AVs. Few studies have considered the issue of its expected impacts under a mixed traffic environment. Instead, most of the studies have focused on the impacts of the partial automation levels of AVs (ACC, CACC).

In general, the complete or partial implementation of AVs offers several potential positive impacts that may improve the overall efficiency of the traffic system. However, there are contradictory results about their expected impacts on the traffic flow characteristics in terms of mixed traffic environment. Different studies indicated that compared to the complete environment of RVs, the partial implementation of different types of AVs, mainly the $\mathrm{CAV}$, increase the traffic capacity, improve the traffic flow stability, increase throughput, and decrease the probability of traffic breakdown, including shockwave formation and propagation, and therefore decrease the intensity and quantity of congestion waves. However, those are based on some important factors that should be considered, including penetration rate, $\mathrm{AV}$ characteristics, modeling and operational settings of the $\mathrm{AV}$, and the level of the traffic volume in addition to the impacts of human driving behavior.

Based on the review's main findings, the paper included a policy implication that intended to provide guidance on the interpretation of the main obtained results for the actual future practice and further research interests. In addition, it was concluded that the actual impacts of the implementation of the AV on mixed traffic still need more investigation.

- There are uncertainties about the impacts of the full level of AVs, including CAVs, on the traffic flow under mixed traffic conditions. Therefore, further investigation efforts are highly needed under various urban networks levels, including different types of signalized and non-signalized intersections. Additionally, it is recommended to consider various traffic compositions, including different combinations of different types of AVs and RVs.

- In terms of AV modeling, most of the reviewed studies did not consider lane-changing behavior. Therefore, further investigation efforts are needed to evaluate the impacts of lane-changing modeling of different types of AV under a mixed traffic environment.

- The review indicated that still further investigations are needed on human driving behavior under mixed traffic environments considering different types of AVs.

Author Contributions: Conceptualization, M.A.-T. and N.T.R.; methodology, M.A.-T. and I.R.; software, M.A.-T.; validation, M.A.-T.; formal analysis, M.A.-T.; investigation, N.T.R., M.A.-T., and S.M.R.; resources, M.A.-T. and I.R.; data curation, M.A.-T. and S.M.R.; writing-original draft preparation, M.A.-T.; writing-review and editing, M.A.-T., S.M.R., and I.R.; visualization, N.T.R., M.A.-T., and S.M.R.; supervision, N.T.R. and M.A.-T.; project administration, N.T.R. All authors have read and agreed to the published version of the manuscript.

Funding: This research received no external funding.

Acknowledgments: The authors would like to gratefully acknowledge the support of King Fahd University of Petroleum \& Minerals (KFUPM) in conducting this research.

Conflicts of Interest: The authors declare no conflict of interest. 


\section{References}

1. Narayanan, S.; Chaniotakis, E.; Antoniou, C. Factors affecting traffic flow efficiency implications of connected and autonomous vehicles: A review and policy recommendations. Adv. Transp. Policy Plan. 2020, 5, 1-50. [CrossRef]

2. Olia, A.; Razavi, S.; Abdulhai, B.; AbdelGawad, H. Traffic capacity implications of automated vehicles mixed with regular vehicles. J. Intell. Transp. Syst. 2018, 22, 244-262. [CrossRef]

3. Lin, Y.; Jia, H.; Zou, B.; Miao, H.; Wu, R.; Tian, J.; Wang, G. Multiobjective Environmentally Sustainable Optimal Design of Dedicated Connected Autonomous Vehicle Lanes. Sustainability 2021, 13, 3454. [CrossRef]

4. Ye, L.; Yamamoto, T. Modeling connected and autonomous vehicles in heterogeneous traffic flow. Phys. A Stat. Mech. Appl. 2018, 490, 269-277. [CrossRef]

5. Xiao, L.; Gao, F. A comprehensive review of the development of adaptive cruise control systems. Veh. Syst. Dyn. 2010, 48, 1167-1192. [CrossRef]

6. Parsa, A.B.; Shabanpour, R.; Mohammadian, A.; Auld, J.; Stephens, T. A data-driven approach to characterize the impact of connected and autonomous vehicles on traffic flow. Transp. Lett. 2020, 1-9. [CrossRef]

7. Fakhrmoosavi, F.; Saedi, R.; Zockaie, A.; Talebpour, A. Impacts of Connected and Autonomous Vehicles on Traffic Flow with Heterogeneous Drivers Spatially Distributed over Large-Scale Networks. Transp. Res. Rec. J. Transp. Res. Board 2020, 2674, 817-830. [CrossRef]

8. Talebpour, A.; Mahmassani, H.S. Influence of connected and autonomous vehicles on traffic flow stability and throughput. Transp. Res. Part C Emerg. Technol. 2016, 71, 143-163. [CrossRef]

9. Zhao, L.; Sun, J. Simulation Framework for Vehicle Platooning and Car-following Behaviors Under Connected-vehicle Environment. Procedia Soc. Behav. Sci. 2013, 96, 914-924. [CrossRef]

10. Yu, G.; Liu, S.; Shangguan, Q. Optimization and Evaluation of Platooning Car-Following Models in a Connected Vehicle Environment. Sustainability 2021, 13, 3474. [CrossRef]

11. Bailey, N.K. Simulation and Queueing Network Model Formulation of Mixed Automated and Non-Automated Traffic in Urban Settings. Ph.D. Thesis, Massachusetts Institute of Technology, Cambridge, MA, USA, 2016. Available online: https: / / dspace.mit.edu/handle/1721.1/107069 (accessed on 24 August 2021).

12. Zeidler, V.; Buck, H.S.; Kautzsch, L.; Vortisch, P.; Weyland, C.M. Simulation of Autonomous Vehicles Based on Wiedemann's Car Following Model in PTV Vissim. In Proceedings of the 98th Annual Meeting of the Transportation Research Board (TRB), Washington, DC, USA, 13-17 January 2019; pp. 13-17.

13. Abdulsattar, H.; Siam, M.R.K.; Wang, H. Characterisation of the impacts of autonomous driving on highway capacity in a mixed traffic environment: An agent-based approach. IET Intell. Transp. Syst. 2020, 14, 1132-1141. [CrossRef]

14. Jones, S.; Philips, B.H. Cooperative Adaptive Cruise Control: Critical Human Factors Issues and Research Questions. 2013. Available online: https:/ /ir.uiowa.edu/drivingassessment/2013/papers/20/ (accessed on 24 August 2021).

15. Duarte, F.; Ratti, C. The Impact of Autonomous Vehicles on Cities: A Review. J. Urban Technol. 2018, 25, 3-18. [CrossRef]

16. Eluru, N.; Choudhury, C.F. Impact of shared and autonomous vehicles on travel behavior. Transportation 2019, 46, 1971-1974. [CrossRef]

17. Hamadneh, J.; Esztergár-Kiss, D. Impacts of Shared Autonomous Vehicles on the Travelers' Mobility. In Proceedings of the 2019 6th International Conference on Models and Technologies for Intelligent Transportation Systems (MT-ITS), Cracow, Poland, 5-7 June 2019; pp. 1-9. [CrossRef]

18. Hamadneh, J.; Esztergár-Kiss, D. The Influence of Introducing Autonomous Vehicles on Conventional Transport Modes and Travel Time. Energies 2021, 14, 4163. [CrossRef]

19. Zheng, F.; Liu, C.; Liu, X.; Jabari, S.E.; Lu, L. Analyzing the impact of automated vehicles on uncertainty and stability of the mixed traffic flow. Transp. Res. Part C Emerg. Technol. 2020, 112, 203-219. [CrossRef]

20. Zheng, F.; Lu, L.; Li, R.; Liu, X.; Tang, Y. Traffic Oscillation using Stochastic Lagrangian Dynamics: Simulation and Mitigation via Control of Autonomous Vehicles. Transp. Res. Rec. J. Transp. Res. Board 2019, 2673, 1-11. [CrossRef]

21. Hawkins, J.; Habib, K.N. Integrated models of land use and transportation for the autonomous vehicle revolution. Transp. Rev. 2019, 39, 66-83. [CrossRef]

22. Calvert, S.C.; Schakel, W.J.; Van Lint, J.W.C. Will Automated Vehicles Negatively Impact Traffic Flow? J. Adv. Transp. 2017, 2017, 1-17. [CrossRef]

23. Hoogendoorn, R.; van Arem, B.; Hoogendoom, S. Automated Driving, Traffic Flow Efficiency, and Human Factors. Transp. Res. Rec. J. Transp. Res. Board 2014, 2422, 113-120. [CrossRef]

24. Lu, Q.; Tettamanti, T.; Hörcher, D.; Varga, I. The impact of autonomous vehicles on urban traffic network capacity: An experimental analysis by microscopic traffic simulation. Transp. Lett. 2020, 12, 540-549. [CrossRef]

25. Liu, Y.; Guo, J.; Taplin, J.; Wang, Y. Characteristic Analysis of Mixed Traffic Flow of Regular and Autonomous Vehicles Using Cellular Automata. J. Adv. Transp. 2017. Available online: https://www.hindawi.com/journals/jat/2017/8142074/ (accessed on 24 August 2021).

26. Van Arem, B.; Van Driel, C.J.G.; Visser, R. The Impact of Cooperative Adaptive Cruise Control on Traffic-Flow Characteristics. IEEE Trans. Intell. Transp. Syst. 2006, 7, 429-436. [CrossRef] 
27. Tientrakool, P.; Ho, Y.-C.; Maxemchuk, N.F. Highway Capacity Benefits from Using Vehicle-to-Vehicle Communication and Sensors for Collision Avoidance. In Proceedings of the 2011 IEEE Vehicular Technology Conference (VTC Fall), San Francisco, CA, USA, 5-8 September 2011; pp. 1-5.

28. Shladover, S.E.; Su, D.; Lu, X.-Y. Impacts of Cooperative Adaptive Cruise Control on Freeway Traffic Flow. Transp. Res. Rec. J. Transp. Res. Board 2012, 2324, 63-70. [CrossRef]

29. Bohm, F.; Häger, K. Introduction of Autonomous Vehicles in the Swedish Traffic System: Effects and Changes Due to the New Self-Driving Car Technology. 2015. Available online: https:/ / www.diva-portal.org/smash/record.jsf?pid=diva2:816899 (accessed on 24 August 2021).

30. Maurer, M.; Gerdes, J.C.; Lenz, B.; Winner, H. Autonomous Driving: Technical, Legal and Social Aspects; Springer: Berlin/Heidelberg, Germany, 2016; Available online: https://library.oapen.org/bitstream/handle/20.500.12657/27811/1002194.pdf?seque (accessed on 24 August 2021).

31. Mena-Oreja, J.; Gozalvez, J.; Sepulcre, M. Effect of the Configuration of Platooning Maneuvers on the Traffic Flow under Mixed Traffic Scenarios. In Proceedings of the 2018 IEEE Vehicular Networking Conference (VNC), Taipei, Taiwan, 5-7 December 2018; pp. 1-4. [CrossRef]

32. Kesting, A.; Treiber, M.; Helbing, D. Enhanced intelligent driver model to access the impact of driving strategies on traffic capacity. Philos. Trans. R. Soc. A Math. Phys. Eng. Sci. 2010, 368, 4585-4605. [CrossRef]

33. Jerath, K.; Brennan, S.N. Analytical Prediction of Self-Organized Traffic Jams as a Function of Increasing ACC Penetration. IEEE Trans. Intell. Transp. Syst. 2012, 13, 1782-1791. [CrossRef]

34. Ntousakis, I.A.; Nikolos, I.K.; Papageorgiou, M. On Microscopic Modelling of Adaptive Cruise Control Systems. Transp. Res. Procedia 2015, 6, 111-127. [CrossRef]

35. Li, Y.; Li, Z.; Wang, H.; Wang, W.; Xing, L. Evaluating the safety impact of adaptive cruise control in traffic oscillations on freeways. Accid. Anal. Prev. 2017, 104, 137-145. [CrossRef] [PubMed]

36. Kerner, B.S. Effect of Autonomous Driving on Traffic Breakdown in Mixed Traffic Flow: A Critical Mini-Review. arXiv 2020, arXiv:2004.06504.

37. Vander Werf, J.; Shladover, S.; Miller, M.A. Conceptual Development and Performance Assessment for the Deployment Staging of Advanced Vehicle Control and Safety Systems. 2004. Available online: https://escholarship.org/uc/item/8hg3b55r (accessed on 24 August 2021).

38. Schakel, W.J.; van Arem, B.; Netten, B.D. Effects of Cooperative Adaptive Cruise Control on traffic flow stability. In Proceedings of the 13th International IEEE Conference on Intelligent Transportation Systems, Funchal, Portugal, 19-22 September 2010; IEEE Society: Washington, DC, USA, 2010; pp. 759-764.

39. Milanes, V.; Shladover, S.E.; Spring, J.; Nowakowski, C.; Kawazoe, H.; Nakamura, M. Cooperative Adaptive Cruise Control in Real Traffic Situations. IEEE Trans. Intell. Transp. Syst. 2013, 15, 296-305. [CrossRef]

40. Arnaout, G.M.; Arnaout, J.-P. Exploring the effects of cooperative adaptive cruise control on highway traffic flow using microscopic traffic simulation. Transp. Plan. Technol. 2013, 37, 186-199. [CrossRef]

41. Le Vine, S.; Zolfaghari, A.; Polak, J. Autonomous cars: The tension between occupant experience and intersection capacity. Transp. Res. Part C Emerg. Technol. 2015, 52, 1-14. [CrossRef]

42. Ye, L.; Yamamoto, T.; Morikawa, T. Heterogeneous Traffic Flow Dynamics under Various Penetration Rates of Connected and Autonomous Vehicle. In Proceedings of the 2018 21st International Conference on Intelligent Transportation Systems (ITSC), Maui, HI, USA, 4-7 November 2018; pp. 555-559.

43. Makridis, M.; Mattas, K.; Ciuffo, B.; Raposo, M.A.; Toledo, T.; Thiel, C. Connected and Automated Vehicles on a Freeway Scenario. Effect on Traffic Congestion and Network Capacity. In Proceedings of 7th Transport Research Arena TRA 2018, Wien, Austria, 16-19 April 2018.

44. Zhou, Y.; Zhu, H.; Guo, M.; Zhou, J. Impact of CACC vehicles' cooperative driving strategy on mixed four-lane highway traffic flow. Phys. A Stat. Mech. Appl. 2020, 540, 122721. [CrossRef]

45. Zhong, Z.; Lee, E.E.; Nejad, M.; Lee, J. Influence of CAV clustering strategies on mixed traffic flow characteristics: An analysis of vehicle trajectory data. Transp. Res. Part C Emerg. Technol. 2020, 115, 102611. [CrossRef]

46. Jin, S.; Sun, D.-H.; Zhao, M.; Li, Y.; Chen, J. Modeling and stability analysis of mixed traffic with conventional and connected automated vehicles from cyber physical perspective. Phys. A Stat. Mech. Appl. 2020, 551, 124217. [CrossRef]

47. Friedrich, B. The Effect of Autonomous Vehicles on Traffic. In Autonomous Driving; Gabler: Oslo, Norge, 2016 ; pp. $317-334$.

48. Wagner, P. Traffic Control and Traffic Management in a Transportation System with Autonomous Vehicles. In Autonomous Driving; Gabler: Oslo, Norge, 2016; pp. 301-316.

49. Chen, D.; Ahn, S.; Chitturi, M.; Noyce, D.A. Towards vehicle automation: Roadway capacity formulation for traffic mixed with regular and automated vehicles. Transp. Res. Part B Methodol. 2017, 100, 196-221. [CrossRef]

50. Elvarsson, A.B. Modelling Urban Driving and Stopping Behavior for Automated Vehicles. 2017. Available online: https://ethz.ch/ content/dam/ethz/special-interest/baug/ivt/ivt-dam/publications/students/501-600/sa597.pdf (accessed on 24 August 2021).

51. Stern, R.E.; Cui, S.; Monache, M.L.D.; Bhadani, R.; Bunting, M.; Churchill, M.; Hamilton, N.; Haulcy, R.; Pohlmann, H.; Wu, F.; et al. Dissipation of stop-and-go waves via control of autonomous vehicles: Field experiments. Transp. Res. Part C Emerg. Technol. 2018, 89, 205-221. [CrossRef] 
52. Zheng, Y.; Wang, J.; Li, K. Smoothing Traffic Flow via Control of Autonomous Vehicles. IEEE Internet Things J. 2020, 7, 3882-3896. [CrossRef]

53. Zong, S. How Connected Autonomous Vehicles Would Affect Our World?-A Literature Review on the Impacts of CAV on Road Capacity, Environment and Public Attitude. In Proceedings of the 7th International Conference on Traffic and Logistic Engineering, Paris, France, 21-23 August 2019; Volume 296, p. 01007.

54. Nikolos, I.K.; Delis, A.I.; Papageorgiou, M. Macroscopic Modelling and Simulation of ACC and CACC Traffic. In Proceedings of the 2015 IEEE 18th International Conference on Intelligent Transportation Systems, Gran Canaria, Spain, 1-15 September 2015; pp. 2129-2134.

55. Gora, P.; Katrakazas, C.; Drabicki, A.; Islam, F.; Ostaszewski, P. Microscopic traffic simulation models for connected and automated vehicles (CAVs) -State-of-the-art. Procedia Comput. Sci. 2020, 170, 474-481. [CrossRef]

56. Soteropoulos, A.; Berger, M.; Ciari, F. Impacts of automated vehicles on travel behavior and land use: An international review of modelling studies. Transp. Rev. 2019, 39, 29-49. [CrossRef]

57. Wang, J.; Peeta, S.; He, X. Multiclass traffic assignment model for mixed traffic flow of human-driven vehicles and connected and autonomous vehicles. Transp. Res. Part B Methodol. 2019, 126, 139-168. [CrossRef]

58. Milakis, D. Long-term implications of automated vehicles: An introduction. Transp. Rev. 2019, 39, 1-8. [CrossRef]

59. Howlett, M.; Ramesh, M.; Perl, A. Studying Public Policy: Policy Cycles and Policy Subsystems; Oxford University Press: Oxford, UK, 2009. [CrossRef]

60. Taeihagh, A.; Lim, H.S.M. Governing autonomous vehicles: Emerging responses for safety, liability, privacy, cybersecurity, and industry risks. Transp. Rev. 2018, 39, 103-128. [CrossRef]

61. Sala, M.; Soriguera, F. Macroscopic Modeling of Connected Autonomous Vehicle Platoons under Mixed Traffic Conditions. Transp. Res. Procedia 2020, 47, 163-170. [CrossRef] 